Community paediatrics

\title{
Community child health in crisis
}

\section{Bannon}

\section{Commentary on the leading article by Mather (see pp 697-704)}

n her personal view, Dr Mather has hit the nail on the head when she describes the world as currently viewed by many community paediatricians. ${ }^{1}$ On the one hand, most paediatricians who hold a post with the word "community" somewhere in their title or job description would talk enthusiastically about the uniquely varied, challenging, and frequently rewarding nature of their clinical work. However, they will also readily identify and expand on the frustrations, anxieties, and challenges identified within the paper.

Community child health does appear to have somewhat of an image problem. It can be difficult to describe in a few sentences to a layperson what it is exactly that community paediatricians do. Colleagues in other braches of child health would have no difficulties in this respect and would accurately convey an easily understood image of their profession by saying "I look after sick newborn babies" or "I am a children's doctor who specialises in diseases of the nervous system". I challenge any community colleague to summarise their work in a similar fashion without resorting to such jargon as "social paediatrics", "health promotion", or "child advocacy", terms which, though admirable in their own right, do not easily lend to an appreciation of who community paediatricians are or of their unique contribution to child health and welfare. This confusion may not be limited to the public. I remember some years ago referring a child with chronic nephrotic syndrome to a tertiary centre and receiving a letter from the head of department expression surprise and concern that a "community" paediatrician should undertake the continuing management of a child with an acute illness (the inference being possibly that the attention of a real paediatrician was required!).

A survey of community paediatricians would reveal considerable variation with respect to titles, job descriptions, responsibilities (immunisation, child protection, disability, school health, etc), day to day activities, where they work, and more recently with the arrival of Primary Care Trusts, who employs them. Variation is not necessarily a bad thing (especially if it results from local health needs), but does lead to muddled views regarding community child health as a bona fide specialty. Finally, the specialty may admittedly not be as glamorous to the uninitiated as, say, neonatology or intensive care work. It would be hard to imagine a successful TV series based around the activities of a community child health department!

It is indeed of concern that the specialty is not attracting trainees in sufficient numbers to meet perceived future need. The reasons for this must be identified and addressed. Apart from problems resulting from image, it should be remembered that the lead child protection role in most districts lies with a community paediatrician. There is anecdotal evidence that many such posts remain vacant following the publication of Lord Laming's inquiry into the death of Victoria Climbié. ${ }^{2}$

Like other specialties, there are problems with respect to recruiting and retaining an appropriate workforce that is fit for the job that must be done. (General practice is experiencing similar difficulties.) Much of the day-to-day work in community child health was previously undertaken by staff grade doctors (and prior to this, by clinical medical officers). The majority of these doctors have now retired and have taken with them their unique and specialised knowledge, skills, and expertise. They have largely been replaced with either consultants or training posts. Some of their work, such as immunisation, has by default become the responsibility of health visitors and school nurses (where available). Interestingly enough, a similar situation has occurred in Canada. ${ }^{3}$ There is now a gap in the medical community child health workforce whereby it is difficult to identify a group of doctors willing or able to do such responsibilities as immunisation, especially BCG administration, child health surveillance, and school health. Some of these represent activities that the College (quite rightly) would consider to represent tasks of little or no educational value.

The entire issue of training represents another challenge for community child health, especially in the light of Modernising Medical Careers and the current review of postgraduate medical education. ${ }^{4}$ Community child health is now recognised as a subspecialty in its own right. This means that after a period of basic training, further time must be spent in acquiring the additional knowledge and skills required of a community paediatrician. Although a curriculum is being agreed, successful training is entirely dependent on there being sufficient slots in training programmes with appropriate input from trainers being available. However, Modernising Medical Careers may also represent a recruitment opportunity for the specialty. One of the stated aims of the second foundation year is to provide young doctors with "tasters" of different specialties with the objective of widening their experience and perhaps also to allow them to consider career options in specialties that they may not have previously encountered. A well organised period of three or four months in the second foundation year that would provide a meaningful experience of community child health could enhance future recruitment into the specialty.

Like any other specialty, community child health needs to both roll with the punches and move with the times in order to survive. Not only do diseases and populations change, but so also does the workforce and the way in which it is managed. Dr Mather clearly states the tasks and challenges that face all paediatricians in terms of addressing childhood morbidity in the twenty first century. Some diseases have all but disappeared (but still can be seen in children recently arrived from developing countries); others are making a comeback, while newer disorders (such as the health consequences of childhood obesity) now also need attention. It would be naïve to believe that the workforce of some years ago could be fit for the purpose of addressing current challenges in child health. The problems that beset community child health should therefore be addressed as a workforce issue. The previously published $A$ workforce of all the talents could provide some guidance in this respect. ${ }^{5}$ Ideally a workforce should be configured in order to best meet the health needs of the local population. It is self evident that there will never be enough consultant community paediatricians (in their current form) in post to meet all of the challenges described by Dr Mather. It would seem reasonable that some at least of the tasks currently ascribed to community child health should become more "mainstream" and become part of the remit of general paediatricians. I can see no reason why 
general and subspecialist paediatricians should not be able to contribute to statements of educational needs nor liaise effectively with schools, social services, and other agencies. These represent core paediatric skills. Some activities should be assimilated by other professional groups. An example of the latter would be the school BCG programme, which in many districts has become the responsibility of school nurse teams.

The problems with image are undoubtedly challenging. However, the reasons why community paediatricians like their work could be explored and shared with registrars in a positive way. We need to ascertain the appeal of community child health. Is it the holistic approach to child health, the variety, or the need for effective team working? Other professional groups (including psychiatry and histopathology) have strived to improve both image and recruitment, and have attempted to make their specialty more attractive. We must do the same for community child health before it is too late.

Arch Dis Child 2004;89:695-696.

doi: 10.1136/adc.2003.042093
Correspondence to: $\operatorname{Dr} M$ Bannon, Oxford PGMDE, The Triangle, Roosevelt Drive, Headington, Oxford OX3 7HP, UK; mibannon@doctors.org.uk

\section{REFERENCES}

1 Mather M. Community paediatrics in crisis. Arch Dis Child 2004:89:697-704.

2 Anon. http://www.victoria-climbieinquiry.org.uk/finreport/finreport.htm.

3 Anon. The community paediatrician - a vanishing breed. http://www.pulsus.com/Paeds/07_04/ wils ed.htm.

4 Department of Health. http://www.doh.gov.uk/ shoconsult/shoconsultresponse.pdf.

5 Department of Health. http://www.doh.gov.uk/ wfprconsult/results.htm.

\section{The human metapneumovirus and respiratory tract infection}

The human metapneumovirus was first isolated in 2001 from children with acute respiratory infections in the Netherlands. A relative of the turkey rhinotracheitis virus (avian pneumovirus), it is a cousin of the respiratory syncytial virus and a more distant cousin of the mumps, measles, and parainfluenza viruses. It has been related to acute respiratory tract infections in children, and some adults, in Canada, Australia, the UK, and the USA. Now a study in Nashville, Tennessee (John V Williams and colleagues. New England Journal of Medicine 2004;350:443-50; see also perspective article, ibid: 431-3) has added to knowledge about the importance of this virus as a respiratory pathogen in children.

At a research primary care clinic over a period of 25 years (1976-2001) a total of 2009 children were followed from birth for an average of 2.5 years. A diagnosis of acute lower respiratory tract infection was made at 1127 patient visits and nasal-wash samples were obtained for viral culture at 687 of these visits. The viruses cultured were respiratory syncytial virus (103), parainfluenza virus (58), influenza virus (32), adenovirus (28), and other viruses (50). No virus was cultured from 408 samples from 321 children. Forty-nine saved, frozen samples from 248 of these 321 children were positive for human metapneumovirus on reverse transcription PCR. Twenty-two of these were confirmed by culture. Only one of 86 controls was positive. The virus caused cough and coryzal symptoms, each present in around $90 \%$. Rhinitis was the most common finding (77\%), followed by wheezing and abnormal ear drum (each 50\%). The clinical diagnoses were bronchiolitis $(59 \%)$, croup (18\%), asthma exacerbation (14\%), and pneumonia (8\%). Chest X-rays were abnormal in seven of 14 children, mostly showing diffuse perihilar infiltrates.

The 49 human-metapneumovirus-positive children were 1.5 to 50 months old (mean 11.6 months, median 6.5 months). Three quarters (36) were infants and 38 of the 49 infections occurred between December and April. Although each of the five viruses (human metapneumovirus, respiratory syncytial virus, parainfluenza virus, influenza virus, and adenovirus) was associated with any of the clinical diagnoses, children infected with human metapneumovirus, respiratory syncytial virus, or adenovirus were most likely to have bronchiolitis and children infected with parainfluenza or influenza viruses were most likely to have croup. [It seems likely that some children with a diagnosis of bronchiolitis in the USA would in the UK be given a diagnosis of pre-school viral wheeze.] Human metapneumovirus was demonstrated in $21 \%$ of virus-positive cases of bronchiolitis, $12 \%$ of virus-positive croup, and $9 \%$ of virus-positive pneumonia. In any given year it accounted for up to $31 \%(0-31 \%)$ of otherwise virus-negative pneumonia. (The figures for human metapneumovirus and other viruses are not strictly comparable because of different methods.)

Human metapneumovirus also caused upper respiratory infection (15\% of a random sample of 261 virus-culture negative children with URTI) but at a later age (mean 19.6 months) than lower respiratory tract infection. 